\title{
Elemental Analysis of Nanomaterial Using Photon-Atom Interaction Based EDXRF Technique
}

\author{
Sanjeev Kumar ${ }^{1}$, Arun Kumar ${ }^{2}$, Mansi Chitkara ${ }^{3}$, I.S. Snadhu ${ }^{3}$ \\ and Devinder Mehta ${ }^{2}$
}

${ }^{1}$ G.G.D.S.D. College Sector-32, Chandigarh

${ }^{2}$ Department of Physics, Panjab University, Chandigarh

${ }^{3}$ Nanomaterials Research Laboratory, Chitkara University, Rajpura 140401, Punjab, India

\begin{abstract}
Presence of trace amount of foreign impurities (both metallic and non-metallic) in standard salts used for sample preparation and during the synthesis process can alter the physical and chemical behavior of the pure and doped nano-materials. Therefore, it becomes important to determine concentration of various elements present in synthesized nano-material sample. In present work, the elemental and compositional analysis of nano-materials synthesized using various methods has been performed using photon-atom interaction based energy dispersive X-ray fluorescence (EDXRF) technique. This technique due to its multielement analytical capability, lower detection limit, capability to analyze metals and non-metals alike and almost no sample preparation requirements can be utilized for analysis of nano-materials. The EDXRF spectrometer involves a $2.4 \mathrm{~kW}$ Mo anode x-ray tube (Pananalytic, Netherland) equipped with selective absorbers as an excitation source and an LEGe detector (FWHM $=150 \mathrm{eV}$ at 5.895 $\mathrm{keV}$, Canberra, US) coupled with PC based multichannel analyzer used to collect the fluorescent X-ray spectra. The analytical results showed good agreements with the expected values calculated on the basis of the precursor used in preparation of nano-materials.
\end{abstract}

\section{INTRODUCTION}

The improved understanding of nano-scale phenomena is critical for the advancement for the various applications in material science. Artificially created nano-structures, including metal and semiconductor nano-wires and nano-tubes have unique mechanical, magnetic, optical and thermoelectric properties. Since their discovery in 1991 [1], carbon nano-tubes (CNTs) have been the basis for various nanoscale devices such as field effect transistors [2-5], heterojunctions [6,7] and nanocomputing applications $[8,9]$. Nano-tubes can efficiently transport electrons with optical excitation via their interesting one-dimensional structures. Current fabrication methods yield nano-tubes with a range of diameters $(\sim 20-300 \mathrm{~nm})$ and different rolling orientations, resulting in the unpredictability of producing metallic or semiconducting nano-tubes [10]. Controlling the diameter and chirality in the nanotubes is difficult. As the electric properties of one-dimensional semiconducting structure are controlled by their diameter [11], therefore these techniques are not suitable for nanotubes. Also, the controlled and long-term stable doping of nano-tube is very challenging. Nano-wires have been gaining a lot of attention as alternatives to CNTs because their growth is easier to control and have been relatively easier to dope with suitable impurities. Nano-tubes

\footnotetext{
Journal of Nuclear Physics, Material Sciences, Radiation and Applications

Vol. 1, No. 1

August 2013 pp. $61-70$
}

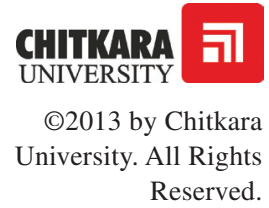


Kumar, S.

Kumar, A.

Chitkara, M.

Snadhu, I.S.

Mehta, D. and nano-wires of various materials can be synthesized using template-based approach and chemical methods. Different nano-structures are extensively characterized using techniques such as high-resolution Transmission Electron Microscopy (HR-TEM) and Field Emission scanning electron Microscopy (FE-SEM). The particle size and shape of the nano-structure material will be determined using x-ray diffraction (XRD) analysis. In addition, the elemental analysis and composition of the nano-structure material is further verified using $\mathrm{x}$-ray emission techniques.

One of the important classes of techniques in elemental analysis is based on photonatom interaction apart from nuclear reaction activation analysis and electron/ioninduced x-ray emission. Following photoionization of inner-shells, the emitted characteristic $\mathrm{x}$ rays or Auger electrons are measured, and used for identification and quantification of the elements. The energy dispersive $\mathrm{x}$-ray fluorescence (EDXRF) technique [12-18], involving measurement of characteristic $\mathrm{x}$ rays from the sample using semiconductor detectors has been well established to determine the elemental concentrations of various elements simultaneously. In case of all the elements present in the sample emit fluorescent $\mathrm{x}$ rays detectable by semiconductor detectors, one can make use of the $\mathrm{x}$ rays to determine concentration of these elements in the sample and hence, thickness of the sample using EDXRF technique. The energy dispersive $\mathrm{x}$-ray fluorescence (EDXRF) is a rapid, sensitive and non-destructive technique for providing semi-quantitative and qualitative information of the trace elements present in the sample. EDXRF technique cannot be used for elements whose lowenergy characteristic $\mathrm{x}$ rays are not detectable by the generally available detectors. The elastic and inelastic scattering are other important modes of photon interaction with matter and also have applications in material characterization $[12,19,20]$. The elastic-scattering measurements in the x-ray energy region, i.e., below $100 \mathrm{keV}$ can be used for Z-dependent characterization of materials, while the inelastic-scattered $\mathrm{x}$ rays can be used for measurements of several physical quantities such as electron density, target mass, and mass density. The RRS is still being explored for applications in chemical speciation of samples [21,22]. The other important point is that the attenuation cross-section $\left(\mathrm{cm}^{2} / \mathrm{g}\right)$ in $\mathrm{H}$ is higher by a factor of $\sim 2$ as compared to that for other elements at photon energy above $20 \mathrm{keV}$. This is because mass of the atom is mainly contributed by the nucleons and scattering is mainly due to the electrons. For $\mathrm{H}$, the ratio of number of electrons to number of nucleons is very different from the other elements. Hence, the information regarding attenuation of photons can be exploited to estimate abundance of $\mathrm{H}$ in hydrogen-rich samples [20]. This property can be used to measure $\mathrm{H}$ in hydrogen-rich compounds like paraffin wax target. The $\mathrm{x}$-ray and $\gamma$-ray transmission methods are suitable for bulk thickness [12]. These can be used in conjunction with the EDXRF and supplement it for limited number of low-Z elements. At the low photon energies, photoionization is the major contributor to their attenuation in matter. Attenuation measurements have the advantage of being independent of enhancement type matrix effects observed in EDXRF analysis. The attenuation measurements require relatively less measurement time and weaker photon source. Furthermore, the energy resolution of the detector is not a limitation 
in such measurements. However, for measuring thickness of the low-Z sample or a sample with low-Z material used as coating and/or backing on a high-Z substrate, one can preferably make use of the attenuation of low energy photons. One should be careful regarding the RRS contribution to attenuation measurements at incident photon energies in the lower vicinity of the electron threshold of the element.

In the present work, the EDXRF technique and attenuation method have been used for analysis of nano-structures. The following measurements have been done (i) Measurements of Ag in thin PVA (polyvinyl alcohol) Ag nano-composite films and (ii) Elemental analysis of some template synthesized nano-wires and nano-tubes using EDXRF technique. These analyses are required to check the possibility of some contamination intruded left-over during synthesis of nano-materials.

\section{MEASUREMENTS OF THIN AG NANO-PARTICLE FILMS}

The PVA (Polyvinyl alcohol)-Ag nano-composite samples were prepared by the nanoscience group of the Physics Department, Kurukshetra University to study their optical and electrical properties. Ag nano-particles were prepared in water by chemical reduction of silver nitrate $(0.01 \mathrm{M}$ solution) with sodium borohydride $(\mathrm{NaBH} 4$, $0.001 \mathrm{M}$ solution). The $0.3 \%$ solution of PVP (Polyvinyl Pyrodine) solution is added as a stablising agent. Further, PVA-Ag nanocomposites were prepared by dissolving 2 gm of PVA in different volume of Ag colloidal. PVA-Ag films were prepared using solgel method and spin coating. TEM measurements were done for the size measurement of the Ag nano-particles prepared in water. Nano-particles were found relatively monodisperse and relatively spherical. The average size of the particles was found to be $20 \mathrm{~nm} \pm 5 \mathrm{~nm}$. To study the optical properties of the films, the concentration of Ag nano-particles in the prepared films is required.

\section{GEOMETRICAL SET-UP AND MEASUREMENTS}

The elemental and compositional analysis of the synthesized nano-material samples were carried out using the EDXRF spectrometer involving a $2.4 \mathrm{~kW}$ Mo anode X-ray tube $(60 \mathrm{kV}$, water cooled, PW 2274/22, Pananalytic, The Netherlands) as a source of excitation. The background due to scattered photons was minimized by placing the x-ray tube, target sample and the detector in $90^{\circ}$ reflection mode geometrical arrangement as shown in the Fig. 1. An LEGe detector in horizontal configuration $\left(100 \mathrm{~mm}^{2} \times 10 \mathrm{~mm}, 8-\mu \mathrm{m}\right.$ Be window and FWHM $=150 \mathrm{eV}$ at $5.895 \mathrm{keV}$, Canberra, US) coupled with PC based multichannel analyzer (Multiport II) was used to collect the fluorescent $\mathrm{x}$-ray spectra from the samples. The target was mounted at $45^{\circ}$ with the detector and $\mathrm{x}$-ray tube axis. The $\mathrm{x}$-ray tube and detector were kept outside the chamber. The alignment of the $\mathrm{x}$ ray tube collimator and chamber collimator was done using laser beam. The x-ray tube is generally operated at $29 \mathrm{kV}$ to avoid excitation of the Sn-collimator with K-Shell binding energy, $\mathrm{B}_{\mathrm{K}}=29.20 \mathrm{keV}$ and $10 \mathrm{~mA}$. The take off angle of the tube window with respect to the horizontal direction is $6^{\circ}$. The spectra
Elemental Analysis of Nanomaterial

Using PhotonAtom Interaction Based EDXRF Technique 
Kumar, S.

Kumar, A.

Chitkara, M.

Snadhu, I.S.

Mehta, D.

64

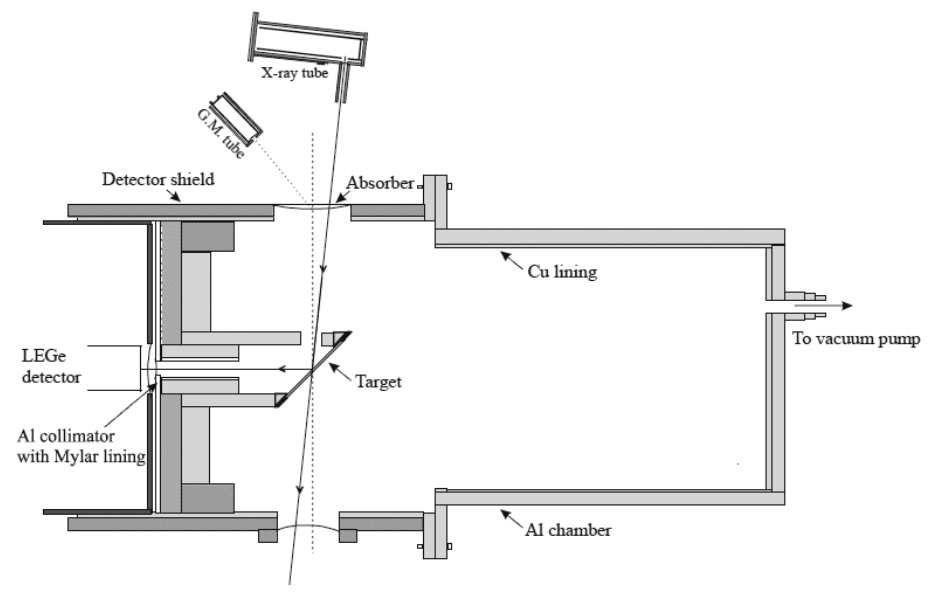

Figure 1: Geometrical arrangement used for the Ag nano-composite thin film measurements.

for each sample were collected for the time periods of $2000 \mathrm{sec}$. The bremsstrahlung and $\mathrm{Mo}-\mathrm{K} \beta(19.65 \mathrm{keV}) \mathrm{x}$ rays emitted from the $\mathrm{x}$-ray tube was reduced by using $\mathrm{Zr}$

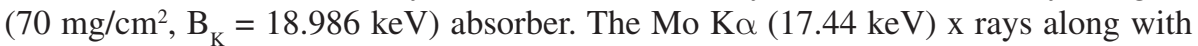
reduced bremsstrahlung were in turn used to excite the characteristic x-ray of elements present in the samples. A G.M. counter facing the incident beam absorber mounted on the chamber was used to monitor the incident beam flux from the x-ray tube. The thickness of the Ag-nano particle film was expected to be in the range $0.5-2.5 \mu \mathrm{g} / \mathrm{cm}^{2}$. As the Mo X-ray tube has the intense Mo K X-rays and bremsstrahlung in the $\mathrm{Ag} \mathrm{K}$ $\mathrm{X}$-ray region, and $\mathrm{Ag}$ excitation is only by the bremsstrahlung, i.e., the detection limit was poor to detect $0.5 \mathrm{mg} / \mathrm{cm}^{2}$ thick Ag target. To handle this problem, an absorber of ${ }_{39} \mathrm{Y}\left(60 \mathrm{mg} / \mathrm{cm}^{2}\right)$ with $\mathrm{B}_{\mathrm{K}}=17.038 \mathrm{keV}$ was used to suppress the Mo $\mathrm{K} \alpha \mathrm{x}$ rays and bremsstrahlung in the region of $\mathrm{Ag} \mathrm{K}$ x rays. This has also significantly reduced the excitation bremsstrahlung. The tube voltage was increased so that the hump due to bremsstrahlung is moved to higher energy region, i.e., away from the region of interest. The x-ray tube was finally operated at $45 \mathrm{kV}$ for the present measurements. This exercise resulted in improved peak-to-background ratio and observation of $\mathrm{Ag}$ $\mathrm{K} \alpha$ x-ray peak to become visible well above the background even for the thinnest available target $\sim 0.5 \mathrm{~g} / \mathrm{cm}^{2}$ as shown in Figs. 2(a) and (b), respectively.

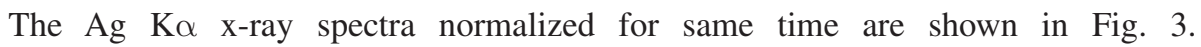
The self absorption correction factors for the thickness of the targets are negligible for the incident photons and emitted Ag K x rays. Spectra for the standard Ag targets (thickness = 99 and $263 \mu \mathrm{g} / \mathrm{cm}^{2}$; Micromatter, US) were also taken and used for deducing thickness of the Ag nano-particle films by unitary method. 


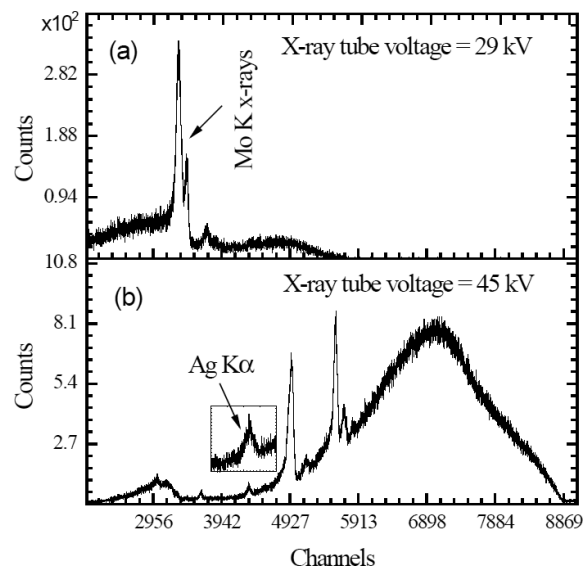

Elemental Analysis of Nanomaterial

Using Photon-

Atom Interaction

Based EDXRF

Technique

Figure 2: Typical spectra for Ag nano-sample (a) using Mo anode X-ray tube at $29 \mathrm{KV}$ (b) using Mo anode x-ray tube with 39Y absober at $45 \mathrm{KV}$.

\section{EVALUATION PROCEDURE}

The measured differential cross sections for the $\mathrm{Ag} \mathrm{K \alpha} \mathrm{X}$-ray photons were evaluated using the relation

$$
\left(\frac{d \sigma}{d \Omega}\right)=\frac{N}{4 \pi I_{o} G \varepsilon m \beta}
$$

where $N$ is the number of counts/s under the $\mathrm{K} \alpha \mathrm{X}$-ray peak, $I_{o} G$ is the intensity of photons falling on the portion of target visible to the detector, $\varepsilon$ is the detector efficiency $\mathrm{keV}, m$ is thickness of the target foil in $\mathrm{g} / \mathrm{cm}^{2}$, and $\beta$ is the absorption correction factor which accounts for absorption of the incident and the elastic scattered photons in target. The values of absorption correction factors is given by expression

$$
\beta_{M}^{R}=\frac{1-\exp \left[-\left\{\left(\mu_{i n} / \rho\right)_{1} / \cos \theta_{i}+\left(\mu_{e m} / \rho\right)_{2} / \cos \theta_{e}\right\} m\right]}{\left\{\left(\mu_{i n} / \rho\right)_{1} / \cos \theta_{i}+\left(\mu_{e m} / \rho\right)_{2} / \cos \theta_{e}\right\} m}
$$

where $\mu_{i n}$ and $\mu_{e m}$ are the attenuation coefficients $\left(\mathrm{cm}^{2} / \mathrm{g}\right)$ for the incident photons and emitted characteristic x-rays, respectively. $\theta_{i}$ and $\theta_{e}$ are the angles made by the incident and the scattered photons with the normal to the target surface. As all the spectra were taken under similar conditions, all the terms occurring in Eqn.1 except the count rate for the standard target and the nano-particle sample will cancel. The number of counts under the scattered part of the bremsstrahlung in the spectrum and x-ray counts from the G.M. tube was used to check the stability of the excitation spectrum. After analyzing the spectra for various nano-films, the concentration of Ag nano-particles were found to be $0.97 \%, 0.87 \%, 0.81 \%$ and $0.53 \%$ when 2 gm of PVA dissolved in $18 \mathrm{ml}, 16$ $\mathrm{ml}, 12 \mathrm{ml}$ and $8 \mathrm{ml} \mathrm{Ag}$ colloidal solution respectively. The Amount of Ag present in 
Kumar, S.

Kumar, A.

Chitkara, M.

Snadhu, I.S.

Mehta, D.

66

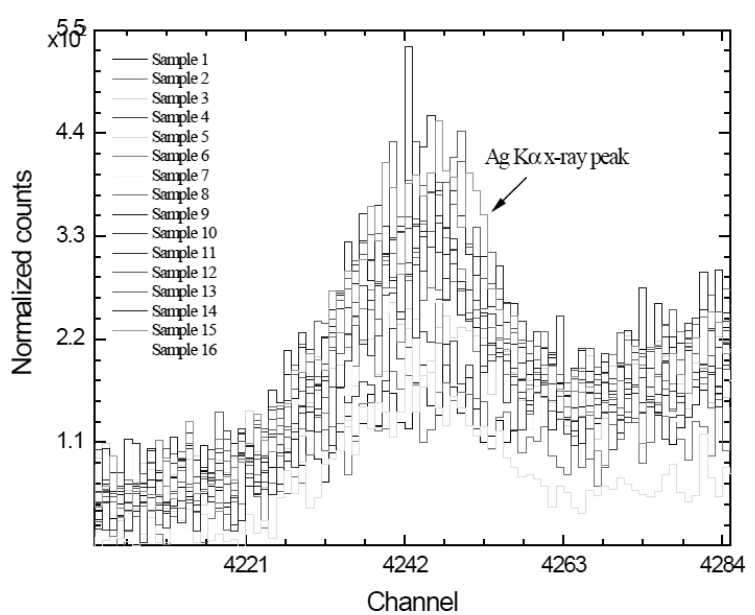

Figure 3: Normalized Spectra of Ag-composite nano-films taken with Mo anode $\mathrm{x}$-ray tube.

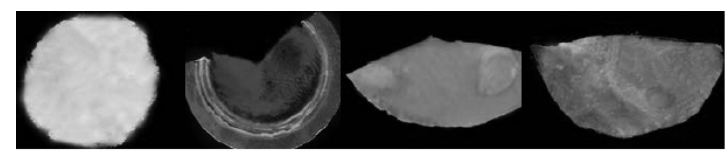

(a)

(b)

(c)

(d)

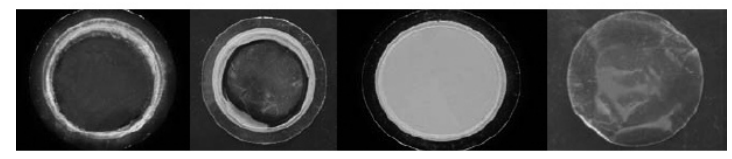

(e)

(f)

(g)

(h)

Figure 4: Photos of template synthesized (a) $\mathrm{AgI}$, (b) $\mathrm{Ag} 2 \mathrm{~S}$, (c) $\mathrm{Ni}$, (d) $\mathrm{Cu}$, (e) $\mathrm{Se}$, (f) Cu2S nano-wires, (g) Al2O3 filter and (h) ion irradiated poly carbonate template.

various Ag nano-particle films are also summarized in Table 1. It is concluded that for the composite sample with lower Ag concentration one should use same portion of the sample for other kind of measurements like UV visible study, TEM measurements etc. to avoid the non-uniformity effects.

\section{ELEMENTAL ANALYSIS OF SOME TEMPLATE SYNTHESIZED NANO-MATERIALS}

The basic principle involved in template synthesized nano-materials is similar to that of producing components through the use of replication. In this technique; desired materials can be synthesized within the pores of the template membranes. If the 

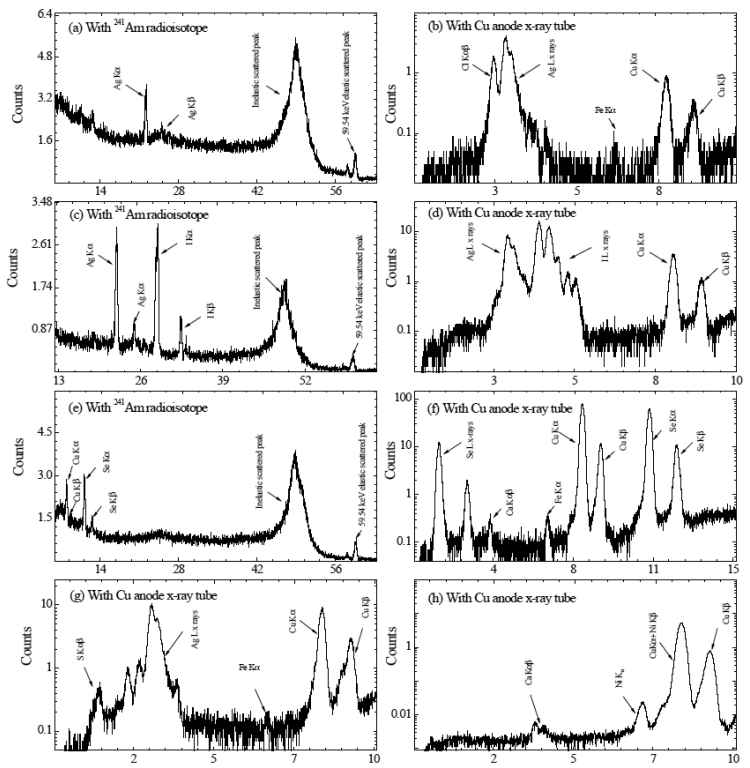

Elemental Analysis of Nanomaterial

Using Photon-

Atom Interaction

Based EDXRF

Technique
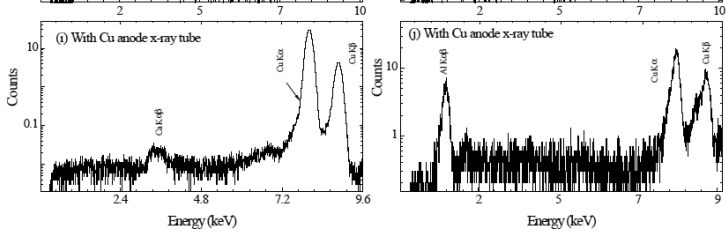

Figure 5: The spectra of $\mathrm{AgCl}$ (a and b), $\mathrm{AgI}$ (c and d), CuSe (e and f), $\mathrm{Ag} 2 \mathrm{~S}$ (g), Ni nano-wires (h), $\mathrm{Cu}$ nano-wire (i) and Al2O3 $\mathrm{j}$ filter excited with $241 \mathrm{Am}$ and $\mathrm{Cu}$ anode $\mathrm{x}$-ray tube.

templates that are used have cylindrical pores of uniform diameter, monodisperse nano-cylinders of desired material are obtained within the void of template material. Depending upon the operating parameters, these nano-cylinders may be solid (nanowires) or hollow (nano-tube). The two basic technique used for the template synthesis of nano-materials are electrochemical deposition and electroless deposition. In the first technique, electrodeposition of a material within the pores of template membrane is obtained by coating one face of the template with a metal film and using same film a cathode for electroplating. The volume of the templates pores are uniformly filled with material and the length of nano-structure can be controlled by varying the amount of deposited materials. The latter technique involvesdeposition of material from the surrounding phase along the cylindrical pores walls of the template surface. After a short deposition times, a hollow tubule (nano-tubes) is obtained within each pore, whereas long deposition times results in solid nano-wires. The inside diameter of the nano-tubes can be controlled by varying the deposition time. After the pores are filled with the desired material, the replica is separated from the membrane matrix either by 
Kumar, S.

Kumar, A.

Chitkara, M.

Snadhu, I.S.

Mehta, D.

Table 1: Amount of Ag present in various Ag nano-particle films.

\begin{tabular}{ccc}
\hline Ag nano-samples & $\begin{array}{c}\text { Amount of solution } \\
\text { taken (in ml) }\end{array}$ & $\begin{array}{c}\text { Amount of Ag } \\
\text { particles (in \%) }\end{array}$ \\
\hline Sample 1 & 2 & $0.24 \%$ \\
Sample 2 & 4 & $0.44 \%$ \\
Sample 3 & 6 & $0.52 \%$ \\
Sample 4 & 8 & $0.53 \%$ \\
Sample 5 & 10 & $0.79 \%$ \\
Sample 6 & 12 & $0.81 \%$ \\
Sample 7 & 14 & $0.87 \%$ \\
Sample 8 & 16 & $0.87 \%$ \\
Sample 9 & 18 & $0.97 \%$ \\
Sample 10 & 20 & $0.97 \%$ \\
Sample 11 & 22 & $0.21 \%$ \\
Sample 12 & 24 & $1.22 \%$ \\
Sample 13 & 26 & $1.27 \%$ \\
Sample 14 & 28 & $1.36 \%$ \\
\hline
\end{tabular}

Table 2: Characteristics of nano-wires used in the present measurements.

\begin{tabular}{cccccc}
\hline S.N. & $\begin{array}{c}\text { Sample used } \\
\text { (nano-wires) }\end{array}$ & $\begin{array}{c}\text { Template } \\
\text { used }\end{array}$ & $\begin{array}{c}\text { Synthesized } \\
\text { technique }\end{array}$ & $\begin{array}{c}\text { Salt used in } \\
\text { prepration }\end{array}$ & $\begin{array}{c}\text { Solvant } \\
\text { materials }\end{array}$ \\
\hline 1. & $\mathrm{Cu}$ & $\mathrm{ITM}$ & Electro-deposition & $\mathrm{CuSO}_{4} \cdot 5 \mathrm{H}_{2} \mathrm{O}, \mathrm{H}_{2} \mathrm{SO}_{4}$ & $\mathrm{H}_{2} \mathrm{O}$ \\
2. & $\mathrm{Ni}$ & $\mathrm{ITM}$ & Electro-deposition & $\mathrm{NiSO}_{4} .5 \mathrm{H}_{2} \mathrm{O}, \mathrm{H}_{3} \mathrm{BO}_{3}$ & $\mathrm{H}_{2} \mathrm{O}$ \\
3. & $\mathrm{AgI}$ & $\mathrm{ITM}$ & Electro-deposition & $\mathrm{AgNO}_{3}, \mathrm{KI}$ & $\mathrm{H}_{2} \mathrm{O}$ \\
4. & $\mathrm{Ag}$ & $\mathrm{Al}_{2} \mathrm{O}_{3}$ filters & Electroless & $\mathrm{AgNO}_{3}$ & $\mathrm{H}_{2} \mathrm{O}$ \\
5. & $\mathrm{Se}$ & $\mathrm{Al}_{2} \mathrm{O}_{3}$ filters & Electro-deposition & $\mathrm{SeO}_{2}, \mathrm{H}_{3} \mathrm{BO}_{3}$ & $\mathrm{H}_{2} \mathrm{O}$ \\
6. & $\mathrm{Ag}_{2} \mathrm{~S}$ & $\mathrm{Al}_{2} \mathrm{O}_{3}$ filters & Electroless & $\mathrm{AgNO}_{3}, \mathrm{Na}_{2} \mathrm{~S}$ & $\mathrm{H}_{2} \mathrm{O}$ \\
\hline
\end{tabular}

peeling it off mechanically or by dissolving the membrane itself in suitable solvent $[23,24]$. More details about template, salt and solvent used for nano-wire preparation is given in Table 2. Among the various host template membranes, ITMs (ion track membranes) act as very good templates for the fabrication of nano/microstructures having desired shape and size [25,26]. The synthetic template involves heavy ion irradiated polymeric foil followed by etching of induced latent tracks by suitable solvent leads to formation of nearly cylindrical pores. Some template synthesized nano-wires used in present measurements are shown in Fig. 4 and typical spectra of each nano-wires and template used as samples are shown in Figs. 5 (a)-(j).

\section{EXPERIMENTAL SET-UPS AND MEASUREMENTS}

The elemental and compositional analysis of template synthesized nano-material samples were carried out using two EDXRF spectrometers as shown in Fig. 1. The low-Z elemental 
analysis was done using EDXRF set-up involved a $2.5 \mathrm{~kW}$ copper anode $\mathrm{x}$-ray tube (Pananalytic made, PW 2274/22, $60 \mathrm{keV}$, water cooled) as a source of excitation. The X-ray tube was operated at $20 \mathrm{kV}$ and $5 \mathrm{~mA}$. The bremstrahlung emitted from the $\mathrm{x}$-ray tube was reduced by using $\mathrm{Ni}(20 \mathrm{mg} / \mathrm{cm} 2)$ absorber. The $\mathrm{Cu} \mathrm{K \alpha}(8.041 \mathrm{keV})$ and $\mathrm{K} \beta(8.907 \mathrm{keV})$ $\mathrm{X}$-ray along with reduced bremsstrahlung were in turn used to excite the characteristic $\mathrm{x}$-ray of elements present in the samples. An LEGe detector in horizontal configuration $(100 \mathrm{~mm} 2 \times 10 \mathrm{~mm}, 8-\mu \mathrm{m}$ Be window and FWHM = $150 \mathrm{eV}$ at $5.895 \mathrm{keV}$, Canberra, US) coupled with PC based multichannel analyzer (Multiport II) was used to collect the fluorescent $\mathrm{x}$-ray spectra from the samples. The background due to scattered photons was further minimized by placing the x-ray tube, target sample and the detector in $90^{\circ}$ reflection mode geometrical arrangement as shown in the Fig. 1. The spectra for each sample were collected for the time periods of $5000 \mathrm{sec}$. The high $\mathrm{Z}$ nano-material samples were also analyzed using the reflection mode geometrical arrangement involving the ${ }^{241} \mathrm{Am}$ annular-source and $\mathrm{Al}$-lined $\mathrm{Pb}$ collimator. The LEGe detectors were used to detect the characteristic $\mathrm{x}$ rays emitted from the sample.

\section{CONCLUSION}

Different aspects of photon-atom based techniques to analyze samples related to nanomaterials are discussed. The EDXRF technique can be used to measure thickness of the PVA-nano-particle composite films required by the Nano-Scientists of the region. The detection limit in the X-ray tube set-up can be improved considerably by using (i) absorbers in front of the x-ray tube to selectively absorb the incident photon flux of in the energy range of interest, and (ii) by selecting the $\mathrm{x}$-ray tube voltage so that hump due to Bremsstrahlung in the spectrum as well as its Ge K x-ray escape is moved away from the region of interest. The composition and purity of the nano-particles prepared using template-based methods was also checked using EDXRF technique.

\section{REFERENCES}

[1] C.S. Iijima, Nature 354, 56 (1991). http://dx.doi.org/10.1038/354056a0

[2] S.J. Tans, A.R.M. Verschueren and C. Dekker, Nature 393, 49 (1998). http://dx.doi.org/10.1038/29954

[3] J.A. Misewich, R. Martel, P. Avouris, J.C. Tsang, S. Heinze and J. Tersoff, Science 300, 783 (2003). http://dx.doi.org/10.1126/science.1081294

[4] K. Liu, M. Burghard, S. Roth and P. Bernier, Appl. Phys. Lett. 75, 2494 (1999). http://dx.doi.org/10.1063/1.125059

[5] Y. Huang, X.F. Duan, Y. Cui and C.M. Lieber, Nano Lett. 21, 01 (2002).

[6] M.S. Fuhrer, J. Nygard, L. Shih, M. Forero, Y.G. Yoon, M.S.C. Mazzoni, H.J. Choi, J. Ihm, S.G. Louie, A. Zettl and P. L. McEuen, Science 288, 494 (2000). http://dx.doi.org/10.1126/science.288.5465.494

[7] Z. Yao, H.W.C. Postma, L. Balents and C. Dekker, Nature 402, 273 (1999). http://dx.doi.org/10.1038/46241

[8] Y. Huang, X.F. Duan, Y. Cui, L.J. Lauhon, K.H. Kim and C. M. Lieber, Science 294, 1313 (2001). http://dx.doi.org/10.1126/science.1066192
Elemental Analysis of Nanomaterial

Using Photon-

Atom Interaction

Based EDXRF

Technique 
[9] M.R. Diehl, S.N. Yaliraki, R.A. Beckman, M. Barahona and J.R. Heath, Angew. Chem. Int. Ed. 41, 353 (2002). http://dx.doi.org/10.1002/1521-3773(20020118)41:2<353::AID-ANIE353>3.0.CO;2-Y

[10] P.C. Collins, M.S. Arnold and P. Avouris, Science 292, 706, (2001). http://dx.doi.org/10.1126/science.1058782

[11] J.T. Hu, L.S. Li, W.D. Yang, L. Manna, L.W. Wang and A.P. Alivisatos, Science 292, 2060 (2001). http://dx.doi.org/10.1126/science.1060810

[12] R. Cesareo, Nucl. Instrum. and Meth. B 150, 571 (1999). http://dx.doi.org/10.1016/S0168-583X(98)01062-3

[13] S. Puri, J.S. Shahi, B. Chand, M.L.Garg, Nirmal Singh and P.N. Trehan, X-ray spectrometry 27, 105 (1998).

http://dx.doi.org/10.1002/(SICI)1097-4539(199803/04)27:2<105::AIDXRS258>3.0.CO;2-W

[14] S. Kumar, S. Singh, D. Mehta, M.L. Garg, P.C. Mangal and P.N. Trehan, X-ray spectrometry 18, 207 (1989). http://dx.doi.org/10.1002/xrs.1300180505

[15] A.G. Karydas and T. Paradellis, X-ray spectrometry 22, 208 (1993). http://dx.doi.org/10.1002/xrs.1300220408

[16] F.J. Pantenburg, T. Beier, F. Hennrich and H. Mommsen, Nucl. Instrum. and Meth. B 68, 125 (1992). http://dx.doi.org/10.1016/0168-583X(92)96063-5

[17] V.D. Martinez, C.M. Hidalgo and R.A. Barrea, X-ray spectrometry 29, 245 (2000). http://dx.doi.org/10.1002/(SICI)1097-4539(200005/06)29:3<245::AIDXRS429>3.0.CO;2-O

[18] M. Manter and M. Schreiner, X-ray spectrometry 29, 3 (2000). http://dx.doi.org/10.1002/(SICI)1097-4539(200001/02)29:1<3::AIDXRS398>3.0.CO;2-O

[19] R. Speller, X-ray spectrometry 28, 22 (1999). http://dx.doi.org/10.1002/(SICI)1097-4539(199907/08)28:4<224::AIDXRS343>3.0.CO;2-F

[20] K. Molt and R. Schramm, X-ray spectrometry 28, 22 (1999). http://dx.doi.org/10.1002/(SICI) 1097-4539(199901/02)28:1<59::AIDXRS310>3.0.CO;2-N

[21] K.E. Miyano, Y. Ma, S.W. Southworth, P.L. Cowan and B.A. Karlin, Phys. Rev. B 54, 12022 (1996). http://dx.doi.org/10.1103/PhysRevB.54.12022

[22] Y. Udagawa and K. Tohji, Chem. Phys. Lett. 148, 101 (1988). http://dx.doi.org/10.1016/0009-2614(88)80283-5

[23] L.D. Pra, E. Ferain, R. Legras and S.D. Champagne, Nucl. Instr. and Meth. B 196, 81.

[24] M. Sima, I. Enclescu, C. Trautmann and R. Neumann, J. Optoelec. \& Adv. Mater. 6, 121 (2004).

[25] B.E. Fischer and R. Spohr, Rev. Mod. Phys. 55, 907 (1983). http://dx.doi.org/10.1103/RevModPhys.55.907

[26] M.E.T. Molares, E.M. Hohberger, C. Schaeflein, R.H. Blick, R. Neumann and C. Trautmann, Appl. Phys. Lett. 82, 2139 (2003). http://dx.doi.org/10.1063/1.1563741 